\title{
Design emocional e significado: a experiência do usuário no processo criativo de Novas Mídias
}

\author{
Emotional design and meaning: the role of user \\ experience in New Media creative processes
}

Franco Araujo Simões ${ }^{1}$ José Armando Valente ${ }^{2}$ 


\section{Resumo}

O presente artigo objetiva discutir o papel central ocupado pela interface do usuário e pelo design de experiência na criação de objetos de Novas Mídias. Diante da hipertrofia de conteúdos e do restrito acesso à atenção do usuário, processos criativos nativos do meio digital devem ocupar-se menos com a criação de novos conteúdos, e dirigir seus esforços para a criação de novas formas de acesso a estes materiais, por meio de filtros, remixes, e principalmente pela criação de novas interfaces e mecanismos que os reorganize. No cenário criativo das Novas Mídias é o sucesso da experiência do usuário que dita quais conteúdos atingirão seus públicos alvo e receberão a atenção desejada.

Palavras-chave: Interfaces Humano-Computador; Design de Interação; Experiência do Usuário; Processos criativos; Design Emocional.

\section{Abstract}

The aim of the following article is to discuss the central role played by user interface and user experience design on the development of new media objects. In face of the accumulation of media content and the restricted access to users' attention, digital-native creative processes should be less concerned with the creation of new content, and direct their efforts to the development of new ways of accessing these materials through filters, remixes and especially by creating new interfaces and mechanisms to reorganize them. On the development of new media products it is the success of the user experience that dictates what content will reach its target audiences and receive the desired attention.

Keywords: Human-Computer Interfaces; Interaction Design; User Experience; User Interface; Creative processes; Emotional Design. 


\section{Introdução}

Ao longo da história do desenvolvimento dos meios de comunicação, por muito tempo coube ao consumidor uma posição passiva e um acesso de certa forma restrito às informações. Até que se tornassem disponíveis, tais conteúdos passavam por rigorosas seleções e curadorias, restando ao público apenas a decisão entre um ou outro canal de televisão ou estação de rádio. Tal modelo comprometia não apenas as opções do espectador, mas dos produtores de conteúdo: dados os altos custos de circulação e o acesso restrito aos veículos de comunicação disponíveis, atingir o público desejado era um privilégio daqueles que poderiam atrair grandes massas e apresentar perspectivas de alto retorno financeiro. Como consequências podemos verificar o sucesso exponencial de grupos musicais que conquistavam espaço nas rádios ao lado das dificuldades dos grupos de estilos menos convencionais; e a seletividade dos canais de notícias - impressos ou televisivos - quanto ao que poderia ser uma matéria ou não.

Com a ascensão do meio digital, no entanto, se desenvolve uma ruptura dessa dinâmica. O aumento do acesso à internet - sobretudo à World Wide Web - proporcionou relativa democratização do acesso à informação e da produção e circulação de conteúdos de mídia. A blogosfera e posteriormente as mídias sociais garantiram ao consumidor - assumindo a postura de usuário - a possibilidade de se expressar na internet, interagir com o conteúdo de outros usuários e até atingir um público. Cada vez mais podemos verificar uma extraordinária quantidade de conteúdos, agora de diversas fontes (usuários ou grandes estúdios) e de diversas naturezas (imagens fixas e imagens em movimento, músicas, textos), sendo distribuídos em canais na rede (sites de notícias, redes sociais, blogs, acervos de museus).

Ao passo em que proporciona uma flexibilização dos conteúdos oferecidos, esta expansão promove uma alteração nas dinâmicas de consumo dos usuários, que agora devem ativamente buscar e selecionar as informações nos diversos canais disponíveis na internet. Neste novo contexto, os recursos escassos não são mais os meios de circulação, mas a atenção do consumidor. Em um ambiente de abundância e constante criação de material midiático, cresce a importância de uma nova modalidade de curadoria, uma mediação entre o público e o conteúdo que ele deseja consumir, uma interface que o auxilie a encontrar em um ambiente prolífico as informações que o interessam. "Isto levou ao próximo estágio da evolução de mídias - a necessidade de novas tecnologias para armazenar, organizar e eficientemente acessar estes materiais." (MANOVICH, 2001, p. 35)

O objetivo do presente artigo é, portanto, discutir o papel central ocupado pela interface do usuário e pelo design de interação na criação de objetos de Novas Mídias neste novo cenário. Diante desta hipertrofia de informações, e do restrito acesso à atenção do usuário, cresce a demanda por um processo criativo que se ocupe menos da produção de novos conteúdos, e dirija seus esforços para a elaboração de novas formas de acesso aos materiais já existentes - seja os reorganizando, por meio de práticas de filtragem ou remix; seja criando interfaces e mecânicas que possibilitem ao usuário novos modos de interagir com estes conteúdos. 
Para desenvolver tal reflexão, o artigo partirá de uma exploração teórica acerca de processos criativos que envolvam a utilização de materiais já existentes na produção de novos discursos e objetos de mídia. Articulada pelo conceito de escolha como fazer artístico elaborado por Bourriaud (2009), a discussão volta-se para a importância da experiência e da interação no consumo de informação neste novo contexto, verificando o papel não passivo do consumidor/usuário. Então, artigo ocupa-se em descrever as características do ambiente digital que viabilizam a interação tratada no artigo - baseando- se em conceitos de Manovich (2001), Murray (2003) e Aarseth (1997). Em seguida, o artigo propõe uma discussão acerca do Design Emocional e dos três níveis de design propostos por Don Norman (2008) - visceral, comportamental e reflexivo - para elaborar uma reflexão a respeito das possíveis variáveis disponíveis ao designer de interação para criar produtos emocionalmente significativos.

Por fim, com a finalidade de ilustrar as reflexões teóricas desenvolvidas, o artigo desenvolverá uma análise de um projeto onde esta dinâmica se aplica. Por conta do emprego de um vasto banco de dados de imagens históricas, e pelas diferentes formas de interação e de emergência de significados que proporciona, o objeto escolhido para análise foi o projeto Old NYC (OLDNYC, 2016) - plataforma interativa de acesso ao acervo de fotografias da New York Public Library que permite aos usuários escolher que fotos observar a partir da rua nas quais foram tiradas.

Portanto, o artigo procura evidenciar a importância das interfaces humano-computador e do design de interação na criação de objetos de novas mídias, explorando - por meio de reflexão teórica e análise de um projeto - de que formas diferentes interfaces e mecanismos podem ser utilizados para dar uma nova vida a conteúdos já existentes ao mesmo tempo que proporciona uma participação não trivial no processo e no resultado.

\section{Desenvolvimento Teórico}

\subsection{Escolha como Processo Criativo}

Com o ready-made, Marcel Duchamp mostrou como o deslocamento de um objeto de um contexto a outro pode alterar de forma drástica seu significado: exposto em um museu, o Urinol de "A Fonte" (1917) deixou de ser um objeto cotidiano interpretado exclusivamente quanto a sua funcionalidade e passou a dialogar com uma nova paisagem cultural que permitiu sua identificação como objeto de arte. Tal ato significou uma ruptura das noções do processo criativo, mostrando que este não se inicia com a folha em branco e não se encerra com uma ilustração, e evidenciando a "equivalência entre escolher e fabricar, entre consumir e produzir" (BOURRIAUD, 2009, p. 20). Assim como no ready-made, práticas de remix e apropriação adotam uma criação baseada na escolha, reorganização e recontextualização, tomando obras de arte e outros objetos culturais pré-existentes como matéria prima, e não como produtos finais. Os artistas deste novo cenário, representados principalmente pela figura do DJ e do programador "contribuem para abolir a distinção tradicional entre produção e consumo, criação e cópia, ready-made e obra original" (Ibid, p.8). 
Considerando a paisagem cultural discutida neste artigo, configurada pelas dinâmicas do ambiente digital e pela hipertrofia de conteúdos, a escolha torna-se central no processo de criação e de consumo de produtos culturais. Formatos que se ocupam em reorganizar conteúdos de forma a atrair os restritos recursos de atenção do usuário concorrem com os que se focam na produção de novos conteúdos, e as práticas de remix e filtragem tornam-se vernaculares no meio digital. Uma imagem disponibilizada na internet não consiste no fim do processo criativo e tampouco representa um produto acabado: sua própria estrutura pode ser manipulada e recriada por inúmeros usuários; e seu significado pode ser alterado - mesmo que sem nenhuma edição - dependendo do contexto em que é apresentada, e dos conteúdos com os quais é relacionada.

Neste consumo dinâmico, a interpretação dos objetos culturais se dá mais pela navegação do que pelos objetos em si, o que atribui a esta camada de mediação (entre os inúmeros conteúdos e os usuários) um grande potencial comunicativo e criativo. Assim, os processos criativos neste novo cenário

não consistem em produzir imagens de imagens - o que seria uma postura maneirista - nem em lamentar que tudo 'já foi feito', e sim em inventar protocolos de uso para os modos de representação e as estruturas formais existentes. (...) A prática do DJ, a atividade do internauta, a atuação dos artistas da pós-produção supõe uma mesma figura do saber, que se caracteriza pela invenção de itinerários por entre a cultura (Ibid, p.14)

É neste contexto que o presente artigo discute o protagonismo do Design de Interação e das Interfaces Gráficas, identificando-as como a camada de mediação citada anteriormente, e verificando sua capacidade de estabelecimento de protocolos e de itinerários por entre conteúdos.

O projeto Old NYC (OLDNYC, 2017), por exemplo, criou uma plataforma que organiza um acervo de fotografias históricas capturadas pelas ruas de Nova York, e oferece ao usuário a possibilidade de acessar as imagens navegando pelo mapa da cidade. A interface identifica em que pontos específicos das ruas as fotografias foram produzidas, agrupa aquelas da mesma localização (produzidas em anos diferentes ou por fotógrafos diferentes) e permite a filtragem das imagens produzidas em um período específico (mostrando apenas imagens produzidas entre 1820 e 1850, por exemplo). Naturalmente, o material utilizado não fora criado para este projeto: as fotografias fazem parte do arquivo da New York Public Library e compõe uma coleção criada em 1920 com o objetivo de observar as transformações que ocorriam na cidade - sobretudo em termos de novas construções e estruturas reformadas e demolidas - por meio do arquivamento de imagens antigas e produção de novas fotografias. Em 2013, o conteúdo desta coleção começou a ser digitalizado e disponibilizado no website da New York Public Library - processo que se prolonga até atualmente (THE NEW YORK PUBLIC LIBRARY, 2017).

Uma nova vida é dada às fotografias por meio da reutilização feita pelo projeto, e novas possibilidades de interpretação deste conteúdo emergem da experiência proporcionada pela interface. Assim, ao invés da produção de novos conteúdos, a 
criação envolvida no projeto Old NYC consistiu na elaboração de uma nova forma de acesso a conteúdos já existentes. O produto passa a ser a Interface criada, que propõe um itinerário por entre as fotografias, e o foco é a própria experiência de navegação dos usuários.

Assim, a obra de arte contemporânea não se coloca como término do 'processo criativo' (um 'produto acabado' pronto para ser contemplado), mas como um local de manobras, um portal, um gerador de atividades. Bricolam-se os produtos, navega-se em redes de signos, inserem-se suas formas em linhas existentes (BOURRIAUD, 2009, p.16)

Em seu artigo "Novas Mídias como Tecnologia e Ideia: Dez Definições", Manovich (2005, p.46) situa esta reutilização como uma atividade da nova vanguarda que teria se iniciado na década de 1980, e dá a esta nova atividade de criação midiática o nome de metamídia "já que usa antigas mídias como seu material primário." (ibid, p.46). O autor enfatiza, ainda, fatores materiais que julga fundamentais para esta transformação estética: "o acúmulo de um enorme ativo de mídia e a chegada de novas ferramentas eletrônicas e digitais que tornavam muito fácil estabelecer o acesso a esse ativo e retrabalhá-lo" (ibid, p.46). O próximo tópico deste artigo discute o segundo fator apontado por Manovich, identificando características específicas destas novas ferramentas eletrônicas que possibilitaram tais mudanças.

\subsection{Princípios do Ambiente Digital}

Para identificar estas características, vou recorrer a princípios descritos por Manovich - em artigos do autor e sobretudo em seu livro The Language of New Media (2001) -, Janet Murray (2004) e Espen Aarseth (1997).

\section{Representação Numérica:}

Conteúdos de mídia criados no meio digital - ou digitalizados para veiculação nele - podem ser descritos em forma de função matemática. Em sua base, objetos de novas mídias, são representados por dígitos, o que desencadeia pelo menos duas consequências relevantes: 1 . Todo objeto de novas mídias está sujeito a manipulação algorítmica; e 2. Os diversos tipos de conteúdo - desde fotografias digitais, a textos e ilustrações digitalizados- compartilham no meio digital uma base comum, permitindo que sejam relacionadas e associadas pelo programador. Esta característica permite, por exemplo, a rápida manipulação de imagens por softwares de edição; e que uma página da web apresente simultaneamente conteúdos de imagem fixa e em movimento, texto e ilustrações.

Além disso, associada à grande capacidade de armazenamento e organização de vastos bancos de dados de informação, a representação numérica trouxe novas formas de categorização de conteúdos: "ao transformar uma imagem em um objeto matemático, computadores nos deram uma nova metalinguagem para imagens - números." (MANOVICH, 2008, p. 8). Os metadados - dados que descrevem da- 
dos - podem então extrapolar a categorização verbocêntrica (lbid, p.3) que nos faz dependente de etiquetas verbais (palavras ou expressões de determinados idiomas) para descrever conteúdos visuais, utilizando para a catalogação dados numéricos contidos nos próprios arquivos. Uma fotografia produzida com um celular possui automaticamente como metadados a data e a hora de captura, e a geolocalização, por exemplo.

\section{Modularidade e Variabilidade:}

"Armazenadas digitalmente ao invés de em um meio fixo, elementos de mídia mantém suas identidades separadas e podem ser montados em numerosas sequências sob o controle de programas" (MANOVICH, 2001, p. 36). Sendo baseados em unidades discretas - que mesmo após organizadas em um produto mantém suas características independentes - os objetos de novas mídias podem estar em constante transformação. Em uma página da internet, por exemplo, cada um dos conteúdos contidos (que podem ser botões, blocos de texto, imagens) mantém sua individualidade, podendo ser alterados separadamente. "Hoje, os exemplos de variabilidade são sites comerciais da rede, programados para personalizar páginas da rede para todo usuário específico que acessar o site, [ou] os remix feitos por DJs de gravações já existentes (...)" (MANOVICH, 2005, p. 28)

\section{Automatização:}

Conforme Janet Murray (2003, p. 74) coloca, o ambiente digital funciona de forma Procedural. Ou seja, seus produtos possuem uma grande capacidade de cumprir tarefas com eficácia e velocidade, e o fazem seguindo procedimentos definidos e contidos em um sistema de regras. Isso possibilita a automatização de atividades, e criação de produtos responsivos à interação do usuário. Com essa automatização é possível armazenar e organizar com eficiência imensos bancos de dados, e criar produtos que se utilizem do acesso a eles. "(...) Mídia armazenada torna-se ativa. Isto é, as operações de busca, ordenação, filtragem, indexação e classificação que antes eram restritas ao domínio da inteligência humana, tornam-se automatizadas." (MANOVICH, 2009, p. 13)

Somada à variabilidade, então, a automatização permite que produtos de novas mídias se alterem constante e dinamicamente. Permite, por exemplo, a criação de websites que possuam uma interface diferente para cada usuário dependendo do aparelho utilizado para acessar (como as páginas de determinados softwares, que identificam o sistema operacional do usuário, e oferecem botões de downloads específicos para cada um); ou ainda a criação de aplicações que se alterem dinamicamente diante da participação do usuário. "(...) a versão customizada criada em resposta ao input do usuário é entregue quase imediatamente" (Ibid, p. 36).

Separação física entre a superfície de leitura e a informação armazenada: 
Em um livro tradicional, por exemplo, ou em uma fotografia analógica, a informação disponível está armazenada na própria superfície de leitura. As palavras a serem lidas estão impressas nas páginas, e as imagens no papel fotográfico. No ambiente digital, no entanto, a superfície de leitura é separada da informação armazenada (AARSETH, 1997, p.10), a mídia oferecida ao usuário é virtual e não existe como objeto material, mas como dados armazenados em discos rígidos - não são impressas de forma definitiva na superfície de leitura.

Para a reflexão deste artigo, vamos considerar em um objeto de novas mídias a existência de pelo menos três instâncias: (1) o conteúdo armazenado - O banco de dados, os materiais contidos nele e os metadados que os descrevem; (2) o mecanismo - os algoritmos que organizam os arquivos e determinam de que forma eles serão utilizados; e (3) a interface - "(...) um lugar onde o contato entre duas entidades ocorre." (ROCHA e BARANAUSKAS, 2003), onde os conteúdos são apresentados ao usuário e onde a interação irá ocorrer. Dos três, apenas a interface é visível aos usuários.

\subsection{O Meio Digital e as Novas Dinâmicas de Consumo}

Grandes quantidades de informações e materiais de diferentes formatos (como textos ou fotografias) podem ser analisados, organizados e armazenados em bancos de dados. Tanto a organização como a análise podem ser feita de forma automática, levando em consideração os metadados contidos em cada arquivo. O conteúdo de um banco de dados pode, então, ser combinado de diferentes maneiras e apresentado ao usuário, dando origem a um produto de mídia - como a página de coleções digitais da New York Public Library, por exemplo, que apresenta fotografias acompanhadas de suas descrições. Este produto, por sua vez, não é final ou definitivo, visto que todas suas partes podem ser transformadas: uma única foto da página pode ser selecionada e vista em tela cheia, ou as fotos apresentadas na página podem ser alteradas por mudanças nos parâmetros de busca.

A separação entre o conteúdo do banco de dados e o que é visto pelo usuário permite que as informações sejam apresentadas aos poucos, diante da participação do usuário. Isso faz com que diferentes conteúdos sejam apresentados a cada momento, e que diferentes relações se estabeleçam entre eles. Na página de coleções digitais do New York Public Library, por exemplo, o usuário pode navegar pelas imagens utilizando palavras chaves, data de criação, data de digitalização, formato (fotografia, ilustração, textos digitalizados), autor, além das diversas coleções em que a imagem pode estar contida. Uma imagem pode estar entre os resultados de uma busca por "Fotografia", mas também em resultados de buscas para "Criada em 1982", "de autoria de Martha Swope", e de determinada coleção. Em cada uma destas buscas, a imagem seria apresentada em conjunto com conteúdos diferentes e as relações criadas entre os eles permitiriam novas interpretações.

Assim, o consumo destes produtos de mídia e a interpretação do usuário se dão pela navegação pelo conteúdo, e por meio de suas escolhas. A interface, então, por ser a camada de mediação que apresenta os conteúdos ao usuário e orienta a experiência de navegação assume um papel central no processo de criação de significado. 
Decisões do designer de interação como "De que forma os conteúdos serão apresentados", "Qual será o posicionamento dos botões" e "Que tipos de mecanismos de interação serão disponibilizados ao usuário" vão definir de que forma o usuário poderá seguir seu itinerário por entre os materiais disponíveis e, portanto, que tipo de interpretações poderão surgir.

Mais do que criar um produto final a ser consumido, o Design de Interação cria o sistema de regras que determina as formas com que o usuário pode interagir com o conteúdo. Desta forma, o designer de experiência se aproxima daquilo que Janet Murray chama de Autor Procedimental: aquele que é responsável pelo procedimento, mas não pelos infinitos resultados que podem surgir com a participação do usuário. "O autor procedimental não cria simplesmente um conjunto de cenas, mas um mundo de possibilidades narrativas" (MURRAY, 2004, p. 149)

\section{Design e Significado}

\subsection{Design Emocional}

Como usuários, nossas atividades envolvem um componente cognitivo - para interpretar e atribuir significado às nossas ações e suas consequências - e um componente afetivo - para a atribuir valor a estas consequências. (NORMAN, 2008, p. 46). Muito embora o primeiro pareça despertar mais atenção dos designers de interação - provavelmente devido à sua relação mais próxima com a produtividade e o sucesso na execução de tarefas - a importância do segundo deve ser levada em consideração, visto que está sempre presente e que seus resultados a nível emocional alteram completamente a forma como pensamos a respeito de objetos e interfaces, e a relação que estabelecemos com eles. Em plataformas de arte interativa, e sistemas cujo objetivo é proporcionar entretenimento ao invés viabilizar a execução de tarefas específicas, o papel do componente afetivo torna-se ainda mais central: as interfaces, nestes casos, devem permitir que o usuário navegue pela plataforma e interaja das formas esperadas de modo eficaz, mas é no valor emocional e simbólico atribuído pelos usuários a estas ações que se encontra o sucesso do produto.

Os elementos emocionais do design são altamente subjetivos, e não existem estratégias universais para medir seus efeitos - medir as reflexões que um usuário teve ou o que sentiu ao utilizar uma plataforma não é tão fácil quanto medir se ele conseguiu ou não completar uma tarefa. No entanto, é fundamental que designers de interação procurem ferramentas para abordá-los em suas interfaces. "Uma pessoa interpreta uma experiência em muitos níveis, mas o que agrada a um pode não agradar a outro. Um projeto bem-sucedido tem de ser excelente em todos os níveis" (Ibid, 2008, p.56)

Para auxiliar na compreensão dos efeitos emocionais em projetos de design e das possíveis formas de desencadeá-los, Don Norman identifica três níveis do sistema cognitivo e emocional que, segundo o autor, estão em constante "operação e lutando entre si": o visceral, o comportamental e o reflexivo (Ibid, 2008, p.56). Ao longo do planejamento de design de um projeto, tendo consciência dos objetivos e 
demandas do produto a ser desenvolvido e conhecimento dos níveis citados acima, um designer de interação pode identificar quais tipos de emoção são compatíveis ao escopo do projeto, e encontrar ferramentas para desencadeá-las em seus usuários. Em relação à preocupação com estes aspectos, Don Norman elabora três níveis de design, que levam os nomes e relacionam-se diretamente com as os três níveis do sistema cognitivo e emocional apontados.

\subsection{Os três níveis de Design}

\footnotetext{
"Cada um dos três níveis de design - o visceral, o comportamental e o reflexivo - desempenha seu papel ao dar forma à nossa experiência. Cada um é tão importante quanto os outros, mas cada um requer uma abordagem diferente por parte do designer". (NORMAN, 2008, p.87)
}

No nível Visceral se formam as primeiras impressões - nele se desenvolvem os efeitos do impacto inicial de uma experiência ou produto. Por ser anterior ao pensamento, este nível refere-se às nossas reações instintivas, e é onde os efeitos da aparência, do som, do odor e do toque predominam. Tratando-se do impacto e das reações iniciais, pode ser descrito como o mais simples de estudar e aplicar - é possível inclusive atribuir justificativas biológicas a efeitos específicos deste nível: sabores amargos podem ser visceralmente detestados devido ao fato de plantas venenosas terem predominantemente este sabor (ibid., 2008, p.89), por exemplo. O design visceral, portanto, ocupa-se de empregar estas reações em favor da experiência desejada, como através do uso de cores saturadas e visualmente agradáveis para atrair, da atribuição do vermelho a mensagens de erro ou do uso de sons altos e abruptos para indicar emergências ou situações que precisam de atenção.

O nível Comportamental diz respeito ao uso e à realização de tarefas. Engloba a experiência do usuário e suas diversas facetas: função, desempenho e usabilidade.

\footnotetext{
"A função de um produto especifica as atividades que ele suporta, para as quais ele foi projetado; (...) $\mathrm{O}$ desempenho diz respeito à medida que o produto faz bem as funções desejadas; (...) A usabilidade descreve a facilidade com que o usuário do produto pode compreender como ele funciona e como fazê-lo funcionar." (Ibid, 2008, p.57)
}

Por convenção, o design Comportamental coloca a função em primeiro lugar. Busca identificar uma tarefa ou um problema a ser resolvido, e elaborar alternativas para resolvê-los da forma mais eficaz. Por se relacionar a questões objetivas, costuma ser procedimental e objetivamente mensurável: sendo definido o objetivo de um produto, pode-se definir a condição de sucesso do usuário e, portanto, identificar de forma quantitativa e precisa o desempenho e a usabilidade.

Assim, o design Comportamental é mais prático e analítico e desenvolve uma relação de codependência com o produto - a respeito do qual deve se questionar constantemente quanto à função e aos objetivos - e com o usuário - que oferece informações sobre desempenho e usabilidade, seu sucesso, de novas necessidades e 
possíveis alterações.

O nível Reflexivo é o mais abrangente e complexo, envolvendo aspectos da experiência e das reações do usuário que são mais difíceis de prever e mensurar quantitativamente. Compreende não apenas o primeiro impacto ou uma situação de uso, mas todo o contexto cultural em que o usuário e o produto estão inseridos.

"Não há nada de prático, nada de biológico nas respostas. As repostas são convenções, aprendidas não importa em que sociedade você habite. (...) Esta é a essência do design reflexivo: tudo está na mente do observador" (Ibid, 2008, p. 111)

É neste nível que o usuário toma consciência da experiência, e que os impactos emocionais e cognitivos se expressam com maior força. Nele o esforço interpretativo do usuário se desenvolve de forma mais ativa, e suas motivações passam a se pautar mais em questões subjetivas do que nas biológicas e práticas que regem os níveis descritos anteriormente. Este nível proporciona, inclusive, certo controle sobre reações geradas pelos outros - um bom exemplo disso é nossa relação com o café, cujo sabor amargo nos parece pouco atraente quando somos crianças mas que, conforme aprendemos a tomá-lo por conta dos efeitos da cafeína, passamos a apreciar cada vez mais.

Por ser o nível que proporciona maior agência ao indivíduo, relaciona-se também a questões de identidade e auto-imagem. Como a motivação para utilizar determinado produto não se limita a praticidade, as decisões possuem significados, e podem expressar muito das vontades e da personalidade de quem as tomou.

Tudo nele diz respeito à mensagem, tudo diz respeito ao significado de um produto ou seu uso. Por um lado, diz respeito ao significado das coisas, às lembranças pessoais que alguma coisa evoca. Por outro, diz respeito à autoimagem e às mensagens que um produto envia às outras pessoas. (Ibid, 2008, p. 107)

Regido pelo mercado, pelas demandas por agilidade e necessidade de atrair e manter grandes quantidades de usuários como consumidores, o Design de Experiência do Usuário geralmente é desenvolvido com foco no nível Comportamental, desenvolvendo fluxos e plataformas preparadas para que os usuários executem tarefas da forma mais prática e rápida possível. $O$ design nesses casos preocupa-se quase unicamente com função, desempenho e usabilidade, e o objetivo é viabilizar aos usuários o cumprimento de suas tarefas, interagindo com a ferramenta apenas pelo tempo necessário.

Os produtos discutidos neste artigo, no entanto, têm como objetivo entreter seus usuários, oferecendo prazer não apenas pela simples execução de uma tarefa ou obrigação de forma prática e objetiva, mas permitindo que o próprio uso e navegação pelas plataformas instiguem reflexões, evoquem lembranças e estimulem emoções. O prazer não é ocasionado ao realizar determinada tarefa por meio do uso do produto, mas na própria experiência de utilizá-lo. Embora todos os níveis de design sejam importantes, o nível reflexivo é fundamental no desenvolvimento destes 
tipos de experiência por convidar o usuário a interpretá-la, relacionando elementos culturais e lembranças ao próprio uso do produto.

Existe um outra distinção entre os níveis: o tempo. Os níveis visceral e comportamental se referem ao 'agora', seus sentimentos e experiências enquanto se está de fato vendo ou usando o produto. Mas o nível reflexivo se estende por muito mais tempo - por meio da reflexão você se lembra do passado e considera o futuro. $\mathrm{O}$ design reflexivo, portanto, tem a ver com relações de longo prazo, com os sentimentos de satisfação produzidos por ter, exibir e usar um produto. (NORMAN, 2008, p.58)

\section{Interface e Experiência em OldNYC}

Por se comportar como a camada de mediação entre as informações armazenadas no banco de dados e os usuários que terão acesso a elas, é na interface que acontece o consumo de conteúdo, onde o usuário desenvolve suas interpretações e de onde o significado emerge. Projetos que se utilizam da curadoria e reorganização de conteúdos pré-existentes em seus processos criativos, definem através da interface quais conteúdos serão disponibilizados e de que formas os usuários serão convidados a interagir.

O uso do Design Reflexivo torna-se, então, evidente. Ao pensar na disposição dos elementos, sobre quais ferramentas de interação deverão ser implementadas e como serão indicadas as possibilidades de participação, o designer não deve levar em consideração apenas o produto ou a situação em que o usuário utilizará a ferramenta: o contexto cultural em que o conteúdo a ser reorganizado foi criado e as possíveis relações que o usuário pode ter com este material são fundamentais para definir suas experiências. Afinal, é nas relações simbólicas criadas entre os conteúdos e nas interpretações realizadas pelos usuários que se encontra o valor destes produtos.

A plataforma OldNYC foi lançada para a web em 2015, pelo desenvolvedor Dan Vanderkam com o objetivo de dar aos usuários uma nova forma de experienciar a coleção fotográfica "Photographic views of New York City" (THE NEW YORK PUBLIC LIBRARY, 2017). O acesso às fotografias de diferentes épocas a partir da navegação de um mapa da cidade possibilitou a exploração e descoberta sobre a história de ruas e construções que fazem parte do cotidiano dos habitantes da cidade. (KIMBALL, 2016)

A nível de conteúdo, o material utilizado pela plataforma é composto de cerca de 80.000 fotografias produzidas nas ruas da cidade de Nova York em um período de cerca de 100 anos. Todas as imagens estão armazenadas no banco de dados (inicialmente fora da vista dos usuários) e categorizadas por metadados como ano, nome do autor, e a geolocalização (com latitude e longitude) de onde foi produzida. O mecanismo da plataforma organiza todos os arquivos associando a geolocalização de cada foto às coordenadas do mapa da cidade. A interface, então, convida os usuários a navegarem por este mapa e apresenta as fotos de pontos específicos das ruas da cidade de acordo com as escolhas do usuário. 


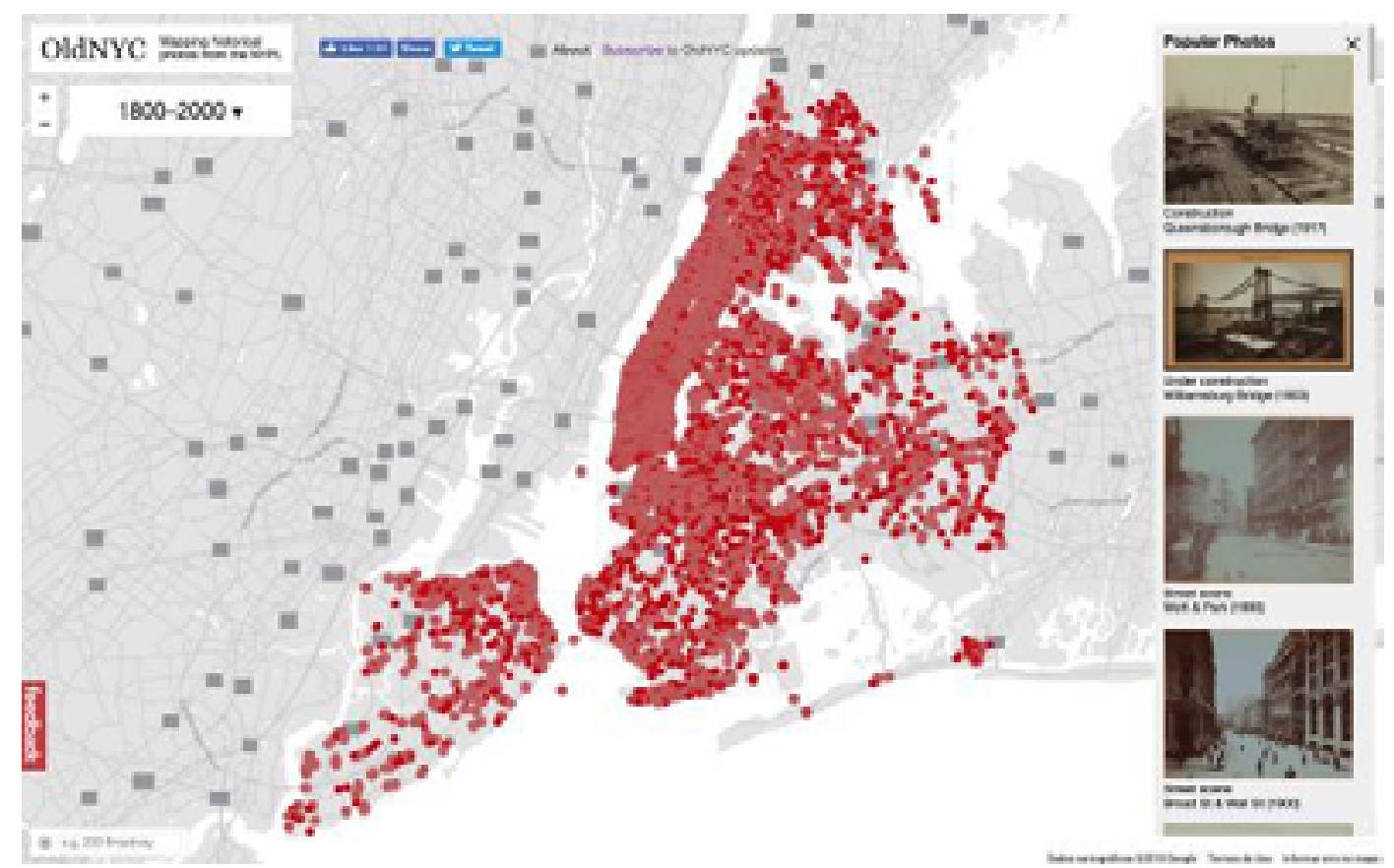

Figura 1: Captura de Tela da página inicial da plataforma OldNYC ${ }^{11}$

A Figura 1 mostra a interface do projeto. Nela podemos ver o mapa da cidade de Nova York, e cada um dos círculos vermelhos indica as coordenadas de um ponto de uma rua específica, que contém uma ou mais fotos da localização. Ao clicar em qualquer um destes pontos, o usuário é apresentado a uma página com as diversas fotografias tiradas naquele lugar. É possível, então, clicar em cada uma das imagens apresentadas, o que revelará suas informações e detalhes - como ano de produção, fotógrafo(a) responsável e em alguns casos uma breve descrição de seu contexto de produção. Além das informações, a janela permite ao usuário o compartilhamento da imagem e da localização nas redes sociais e a possibilidade de criar comentários que poderão ser vistos pelos próximos a acessar a mesma imagem na plataforma (Figuras 2 e 3).

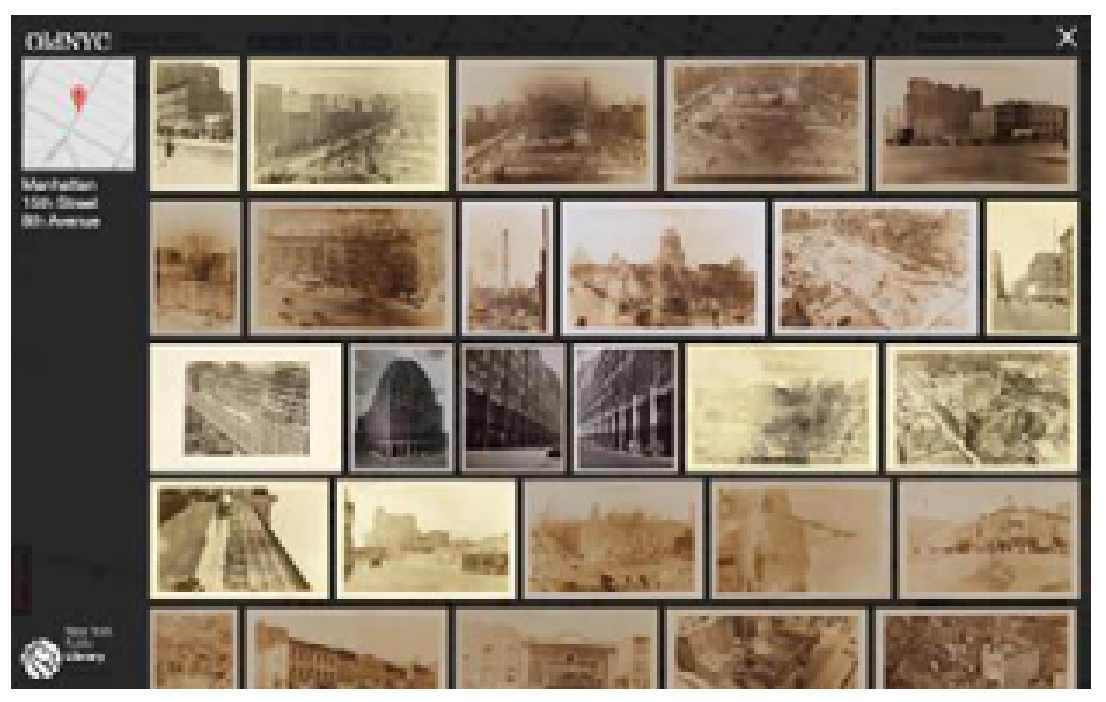

Figuras 2: Captura de Tela da página de fotografias em determinada localização

1 Disponível em: <https://www.oldnyc.org/> 


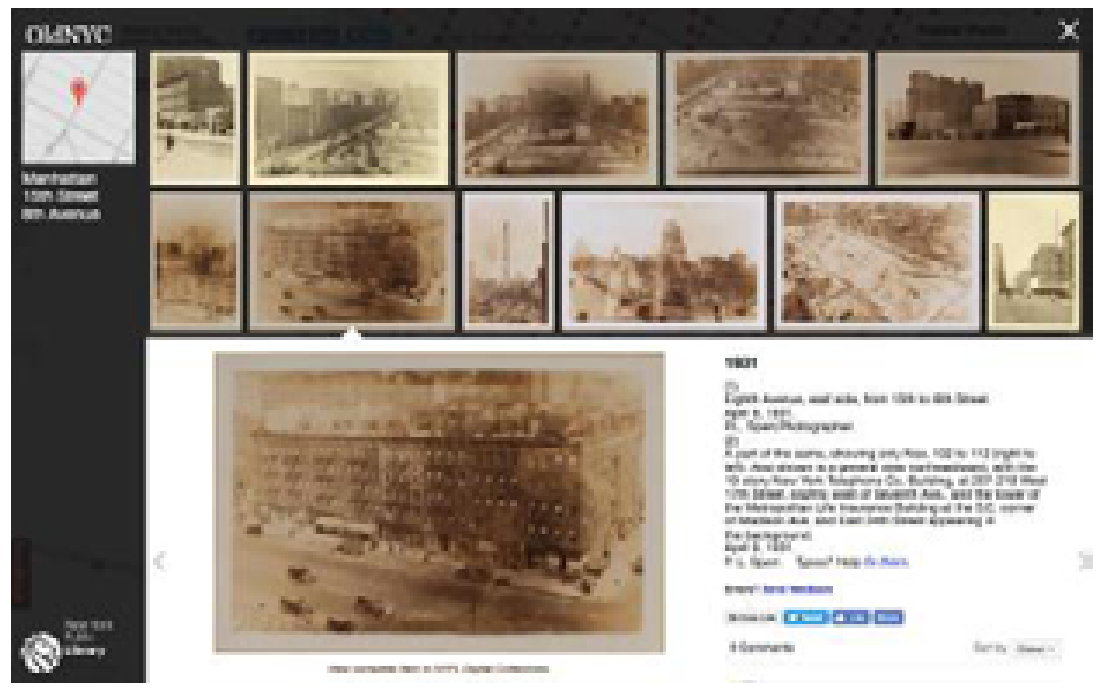

Figuras 2: Captura de Tela da página de fotografias em determinada localização

Além da navegação pelo mapa e seleção de localizações para visualização das imagens, a plataforma disponibiliza outras ferramentas que permitem ao usuário interagir com o conteúdo e filtrá-lo de diferentes formas. Cada uma das ferramentas adicionadas possibilita novas experiências e novas formas de interpretação do conteúdo. A função de seleção por períodos específicos permite ao usuário buscar na interface apenas por fotografias produzidas entre 1914 e 1918, por exemplo (Figura 4). Torna-se possível, então, visualizar imagens do cotidiano das ruas de Nova York durante a Primeira Guerra Mundial. Os efeitos do design de experiência se desenvolvem no nível reflexivo, permitindo que o usuário relacione seus conhecimentos às possibilidades de filtragem, para então visualizar as imagens e interpretá-las em um novo contexto.

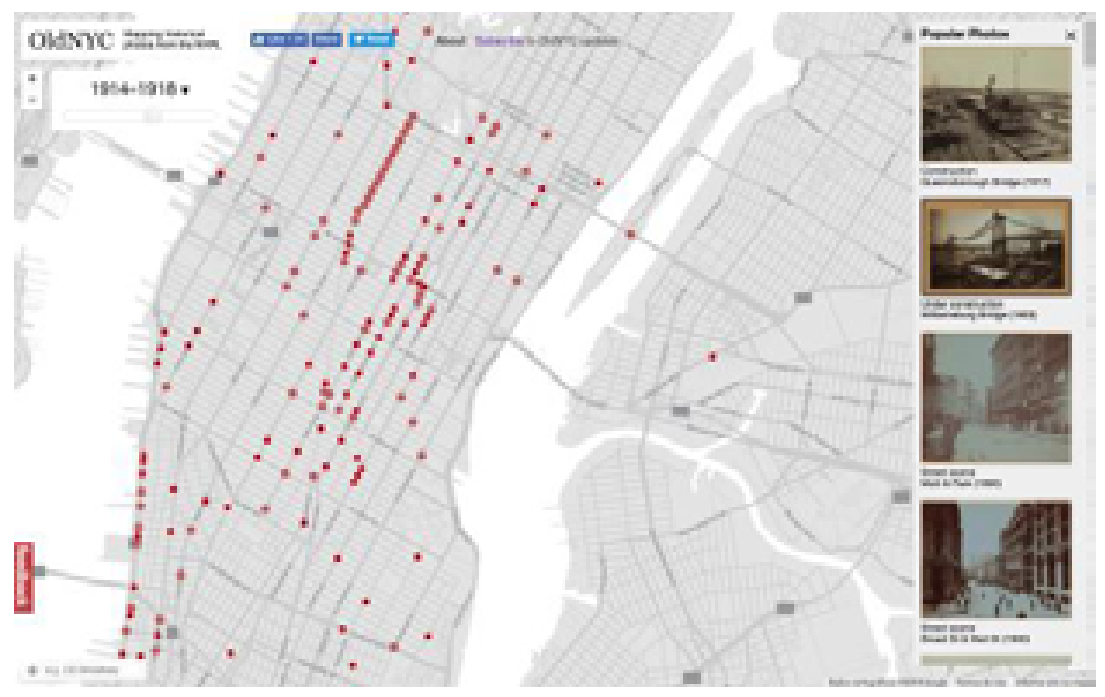

Figura 4: Captura de Tela da interface principal com o filtro de período aplicado para as fotos produzidas entre 1914 e 1918

A função de adicionar comentários às imagens, por sua vez, permite aos usuários que têm alguma conexão com os lugares representados compartilhar suas histórias, e apontar as mudanças que aconteceram com o tempo. Conforme Dan Vanderkam disse em entrevista ao New York Post, "É sempre divertido ver os comentários 
das pessoas. Foi aí que elas cresceram, e elas reconhecem as ruas! Ou eles dizem 'este prédio não existe mais' ou 'Isso ainda está lá, mas ao invés de ser uma loja de departamento é um café'" (VANDERKAM, 2016). A experiência do produto permite um envolvimento do usuário a nível pessoal, possibilitando uma identificação com as imagens veiculadas na plataforma, incentivando a exploração da história da cidade ou até mesmo da rua ou construção específica que habita, além de permitir o compartilhamento desta informação com outros. Aí podemos notar o design reflexivo criando valor para o usuário por permitir a expressão de sua auto-imagem.

Em 2016, o projeto foi expandido com a criação do aplicativo para celular. Apesar de utilizar o mesmo banco de dados e o mesmo mecanismo fundamental de organização dos arquivos, o aplicativo propõe uma mudança no design de interação que altera completamente as formas de experienciar o conteúdo. Nele, a geolocalização do próprio usuário é utilizada para fazer as buscas pelas imagens. A navegação física do usuário pelas ruas da cidade de Nova York determina a navegação pelo arquivo fotográfico no aplicativo, de forma que são apresentadas na interface imagens históricas dos espaços conforme os usuários se locomovem por eles.

Mais uma vez, mesmo sem a criação de novos materiais um novo produto de mídia foi criado a partir do desenvolvimento de novas ferramentas de acesso ao conteúdo. As novas experiências proporcionadas aos usuários deram às fotografias da coleção uma nova vida, e diversas novas formas de significação que não seriam possíveis caso elas continuassem restritas ao espaço da biblioteca. Agora os usuários podem, por exemplo, comparar em tempo real o espaço que ocupam a como ele era no século passado. "Para turistas, o aplicativo é uma nova forma de descobrir uma cidade historicamente rica. E para os locais, é uma ótima forma de visualizar velhas histórias que eles ouviram ao crescer." (POON, 2016)

\section{Considerações Finais}

A reorganização de ativos midiáticos e a alteração dos contextos em que são veiculados podem proporcionar uma constante ressignificação do material. Em uma paisagem cultural marcada pela hipertrofia de conteúdos e pela restrição da atenção dos usuários, a criação de novas formas de filtrar e disponibilizar este material assume grande relevância na produção de objetos de novas mídias. O ambiente digital possui diversas características que viabilizam novas formas de relacionar diversos conteúdos de fontes e naturezas distintas, além de possibilitar a criação de procedimentos que automatizem os processos de organização e reorganização do material a partir da participação do usuário.

O projeto Old NYC nos mostrou a relevância da interface na criação de produtos midiáticos para o meio digital, principalmente do cuidado com um design de experiência que leve em consideração os efeitos dos diferentes níveis do sistema cognitivo e afetivo nas relações emocionais entre o usuário e o produto. Cada ferramenta disponibilizada pelo designer de interação ao usuário altera as formas como este pode interagir com o conteúdo, criando inúmeras possibilidades de navegação e interpretação, e resultando em efeitos emocionais ao longo da experiência. O banco 
de dados de fotografias é o mesmo, mas observar as imagens nos acervos físicos da biblioteca, clicando em um mapa de Nova York sentado na sua casa, ou utilizando um aplicativo no celular conforme anda pela cidade pode acarretar experiências e entendimentos radicalmente distintos.

Desta forma, o artigo procurou evidenciar o potencial semântico das interfaces gráficas e da experiência do usuário nos produtos de novas mídias, discutindo seu papel central no processo criativo e nas novas dinâmicas de consumo. Voltar a atenção a este potencial pode levar a criação de produtos de novas mídias mais interessantes, que reconheçam a linguagem dos elementos de novas mídias e a relevância comunicativa das interfaces, se apropriando do design de interação para criar experiências significativas para os usuários.

\section{REFERÊNCIAS}

AARSETH, Espen J. Cybertext: Perspectives on ergodic literature. Baltimore, Md. London: John Hopkins University Press, 1997. 203p.

BOURRIAUD, Nicolas. Pós-produção: como a arte reprograma o mundo contemporâneo. São Paulo, SP: Martins/Martins Fontes, c2009. 110 p.

KIMBALL, Shana. The OldNYC App Is Here! We Spoke with Its Creators. 2016. Disponível em: < https://www.nypl.org/blog/2016/05/04/oldnyc-app >. Acesso em 27 fev. 2018.

MANOVICH, Lev. Metadata, Mon Amour. 2002. Disponível em: < http://manovich.net/ index.php/projects/metadata-mon-amour >. Acesso em 27 fev. 2018.

MANOVICH, Lev. Novas Mídias como Tecnologia e Ideia: Dez Definições. In: LEÃO, Lúcia. O Chip e o Caleidoscópio: Reflexões sobre as Novas Mídias. São Paulo: Editora Senac, 2005. p. $23-50$.

MANOVICH, Lev. The Language of New Media. Cambridge, MA: MIT, c2001. xxxix, $354 \mathrm{p}$.

MANOVICH, Lev. What Comes After Remix? 2007. Disponível em: < http://manovich. net/index.php/projects/what-comes-after-remix >. Acesso em 27 fev. 2018.

NORMAN, Donald A. Design Emocional: Por que adoramos (ou detestamos) os objetos do dia a dia?; tradução de Ana Deiró. Rio de Janeiro: Rocco. 2008.

OldNYC. Mapping Historical Photos from the NYPL. Disponível em: <https://www. oldnyc.org/>. Acesso em 19 fev. 2018. 
MURRAY, Janet $\mathrm{H}$. Hamlet no Holodeck: o futuro da narrativa no ciberespaço. São Paulo, SP: Editora da UNESP: Itaú Cultural, 2003. 282p.

POON, Linda. Go Back in Time Through New York City With the OldNYC App. 2016. Disponível em: < https://www.citylab.com/life/2016/05/go-back-in-time-through-new-york-city-with-the-oldnyc-app/482286/ >. Acesso em 19 fev. 2018.

ROCHA, Heloisa Vieira da. Design e avaliação de interfaces humano-computador. Coautoria de Maria Cecilia Calani Baranauskas. Campinas, SP: UNICAMP/NIED, 2003.

The New York Public Library. Photographic Views of New York City, 1870's-1970's, from the Collections of the New York Public Library. Disponível em: <https://digitalcollections.nypl.org/collections/photographic-views-of-new-york-city-1870s1970s-from-the-collections-of-the-ne-2\#/?tab=about >. Acesso em 27 de fev. 2018.

VANDERKAM, Dan. Old photos of your NYC location are just a tap away : depoimento. 2016. Disponível em: < http://nypost.com/2016/08/29/old-photos-of-your-nyc-location-are- just-a-tap-away/ >. Acesso em 27 fev. 2018. Entrevista concedida a Hana R. Alberts. 